\title{
SOFTWARE LIVRE COMO FERRAMENTA NO PROCESSO DO ENSINO APRENDIZADO: UMA EXPERIENCIA COM TURMAS DO EJA
}

\author{
Gabriela Carvalho Ribeiro'; Julilma da Silva Reis ${ }^{1}$, Rodrigo de Brito Franco ${ }^{1}$, \\ Maria José Felix ${ }^{2}$, Albertina Marilia A.Guedes', Ubirajara S.Nogueira ${ }^{1}$ \\ ${ }^{1}$ Instituto Federal de Educação, Ciência e Tecnologia do Sertão Pernambucano (IF- \\ SERTÃO) Petrolina - PE- Brazil; \\ ${ }^{2}$ Escola Municipal Professora Luiza de Castro Ferreira e Silva \\ Petrolina - PE - Brazil; \\ \{gabriela.car.ribeiro13, julyreis15a, usnogueira\}@gmail.com, \\ \{rodrigo_britoll, melkray_maria,albertinamarilia\} @hotmail.com,
}

\begin{abstract}
It is noteworthy that we are experiencing a historical period where they are still held in the classroom, activities based on the traditional model of teaching, to the detriment of the innovative model implemented through the use of technological instruments. With the great technological advance, these new technologies must be applied to the school environment, not only as a method of innovation, but as a new teaching-learning method. The objective of this article is to apply Linux Educational software to assist in learning in the Portuguese language and mathematics subjects in classes of EJA (Youth Education) And Adults) in a public school.
\end{abstract}

Resumo. É notório que estamos vivenciando um período histórico onde ainda são realizadas em sala de aula, atividades embasadas no modelo tradicional de ensino em detrimento do modelo inovador executado a partir do uso de instrumentos tecnológicos. Com o grande avanço tecnológico, essas novas tecnologias devem ser aplicadas ao ambiente escolar, não só como um método de inovação, mas, como também, um novo método de ensino-aprendizagem. Tendo em vista os conceitos citados acima e visando um novo método de ensino-aprendizagem com uso da tecnologia, o objetivo deste artigo é aplicar softwares do Linux Educacional no auxílio na aprendizagem nas disciplinas de língua portuguesa e matemática em turmas do EJA (Educação de Jovens e Adultos) em uma escola de ensino públicol.

\section{Introdução}

Atualmente, apesar de ser constante que muitos professores ainda fazem uso de metodologias embasadas no modelo tradicional de ensino, percebemos também que muitos professores buscam fazer uso de tecnologias da informação e comunicação (TIC) nas escolas brasileiras, as mesmas são auxiliares no processo de ensino e aprendizagem de qualquer nível educacional. Essa inclusão é importante já que as TIC estão cada vez 
mais presentes no cotidiano da sociedade. Essa inserção colaborou ainda no rompimento entre o método tradicional de ensino. Tarouco (2004) diz que o uso de TIC, principalmente o computador, enfatiza a participação e experimentação do sujeito na construção do seu próprio conhecimento através das interações que esse tipo de tecnologia proporciona.

O governo brasileiro, buscando inserir as tecnologias nas escolas criou em 1997 o Programa Nacional de Tecnologia Educacional (PROINFO). Tal programa contribuiu com a criação de laboratórios de informática nas escolas da rede pública de ensino objetivando promover o uso das tecnologias como ferramenta de enriquecimento pedagógico no ensino público fundamental e médio. $\mathrm{O}$ computador inserido no ambiente escolar possui boa aceitabilidade possibilitando ainda um aumento na variedade de experiências educacionais.

Entretanto, existe o desafio de unir os docentes junto às tecnologias, especificamente os computadores, pois, como ressalta Valente e Almeida (1997) destacam que a informática ainda não impregnou as ideias dos educadores e, por isso, não está presente em nosso sistema educacional, sendo este ainda um dos obstáculos a serem ultrapassados. Desse modo, o professor necessita incorporar as ferramentas tecnológicas buscando melhorar a qualidade do processo de ensino e aprendizagem a qual se torna uma necessidade na sociedade de constantes inovações.

A Educação de Jovens e Adultos (EJA) é uma modalidade prevista na Lei de Diretrizes e Bases (LDB) no 9394/96 apresenta no seu artigo 37 que: "A educação de jovens e adultos é destinada àqueles que não tiveram acesso ou continuidade de estudos no ensino fundamental e médio na idade própria" (BRASIL, 1996, p.15). Os jovens e adultos que não tiveram a oportunidade de iniciar ou concluir os ensinos: Fundamental I, Fundamental II ou Ensino Médio na idade adequada. De acordo com a referida LDB podem ter acesso a essas etapas da escolaridade por meio de cursos e avaliações voltadas à modalidade de ensino de Educação de Jovens e Adultos (EJA).

Na concepção de Freire (2006), a EJA se caracteriza como "um ato político e um ato de conhecimento, por isso mesmo, um ato criador", no qual o educando busca uma mudança de vida, que vai além da aprendizagem do conteúdo escolar. Esta mudança "parte da necessidade de superar a situação opressora. Isto implica no reconhecimento crítico, na razão desta situação, para que, através de uma ação transformadora que incida sobre ela, se instaure outra, que possibilite aquela busca do ser mais" (FREIRE, 1987).

Segundo Bastos (2016), a cultura digital no contexto da EJA pode estar presente de várias formas visto que pode atuar como elemento integrador em outros componentes curriculares de forma a capacitar os alunos a usar recursos das TIC para desenvolverem pesquisas e expressarem seus conhecimentos através de diferentes mídias (texto, imagem, áudio, vídeo, dentre outros). Além disso, também pode estar presente através de aspectos que dizem respeito à cultura digital em si.

As TIC também podem viabilizar possibilidades de um novo modo de relacionamento entre estudantes e o conhecimento a partir da interatividade. Um grande aliado no processo de inserção das tecnologias no ambiente computacional são os softwares educacionais. Desse modo, a partir do acima exposto esse trabalho teve como objetivo utilizar o software do Linux Educacional como ferramenta de auxílio no ensino aprendizado, nas turmas do EJA em uma escola da rede pública municipal de ensino. 
VI Congresso Brasileiro de Informática na Educação (CBIE 2017)

Anais do XXIII Workshop de Informática na Escola (WIE 2017)

\section{Linux Educacional}

Softwares gratuitos e de código aberto como o Linux possuem uma grandiosidade de aplicativos que podem ser utilizados e modificados para o desenvolvimento de aplicativos educacionais. Freire e Araújo (2009), afirmam que o Linux relaciona-se com a "liberdade de estudar como o programa funciona, e adaptá-lo para as suas necessidades. Acessar o código- fonte é um pré-requisito para esta liberdade". Foi pensando nisso que o Centro de Experimentação em Tecnologia Educacional (CETE) do Ministério da Educação (MEC) desenvolveu o Linux Educacional.

São inúmeras as possibilidades de práticas pedagógicas com o uso dos aplicativos do Linux Educacional. Com os jogos educacionais, por exemplo, é possível trabalhar diversos conteúdos de maneira divertida; por meio dos vídeos do aplicativo TV Escola, os alunos têm a oportunidade de assistir a debates, documentários e diversos outros programas cujos conteúdos podem ser trabalhados em aula. E, ainda, com o aplicativo Domínio Públicos alunos e professores podem ter acesso a diferentes tipos de publicações, tais como: artigos, livros infantis e infanto-juvenis.

Há vários programas para o auxílio do ensino aprendizado, esses programas são voltados ao ensino da programação, física, ciência, geografia, idiomas, matemática, português, multidisciplinar e disponibiliza jogos como forma de diversão para o aluno. Além dos aplicativos há também o pacote do BrOffice que serve para edição de texto, planilhas eletrônicas, apresentação, desenho vetorial e fórmulas. Podemos encontrar também diversos pacotes e programas que atende a necessidade de professores e alunos em diversas formas.

Segundo Carvalho e Ferreira (2008) a aplicação da informática no cotidiano das escolas da rede pública é um fator positivo na transformação do ensino por potencializar o acesso às informações e se apresentar como um meio de comunicação que permite alta interatividade no desenvolvimento das relações entre alunos e professores, como também a reorganização dos métodos de ensino e conteúdos educativos.

Nesse contexto, a inclusão digital na EJA configura-se como um caminho que elevar as possibilidades de inclusão social destes jovens e adultos. Conforme aponta Lèvy (2001), "o ciberespaço será o centro das atividades econômicas, culturais e sociais, tendo a Internet como vetor de reorganização da sociedade que surge para além da cidade física". Portanto, é necessário que todas as pessoas estejam preparadas para atuar neste novo modelo de sociedade, se apropriando dos recursos tecnológicos em suas atividades pessoais e profissionais.

\section{Material e Métodos}

Este estudo teve uma abordagem qualitativa. Segundo Macedo (2009) a pesquisa qualitativa visa à compreensão e interpretação de um fenômeno social onde $o$ pesquisador busca a compreensão do contexto de pesquisa. Neste tipo de abordagem, o pesquisador é compreendido como um dos principais instrumentos de pesquisa.

O trabalho aqui apresentado foi desenvolvido por um grupo de bolsistas integrantes do Subprojeto de Informática do PIBID. Foi realizado no $1^{\circ}$ semestre de 2017 e teve a colaboração de 52 alunos das turmas da EJA de uma escola da rede municipal. O material utilizado para a aplicação dos softwares e coleta de dados foi: Dois Laboratórios de informática com acesso a internet e Linux Educacional e um 
questionário fechado para os alunos onde foi aplicado no final do semestre.

Conforme destaca por Sousa, Souza e Melo (2007), com o advento das Tecnologias de Informação e Comunicação - TIC's em nossa sociedade, muitos recursos são introduzidos no ambiente escolar viabilizando a comunicação e a interação entre professores e alunos, e, alunos entre si. Desse modo, foi socializado com os participantes da pesquisa que o instrumento de coleta de dados para a pesquisa seria um questionário estruturado composto por cinco perguntas objetivas relacionadas ao tema da pesquisa o qual foi disponibilizado para cada aluno através do Google Drive.

As aulas eram realizadas uma vez na semana com duração de 3 horas. Os Softwares utilizados foram: TuxPaint usado como atividade de desenho de alfabetização em computadores, pois, ajuda a manusear o mouse, teclado e a ter uma primeira experiência cognitiva com o computador. O Openoffice Writer utilizado para criação e edição de textos servindo como auxílio também da leitura e a escrita dos alunos. Tuxmath permite a aprendizagem da matemática de forma lúdica e interativa, trabalhando o raciocínio lógico dos alunos. Todos esses softwares estão disponíveis no Linux educacional. Foi planejado trabalhar esses Softwares em etapas da seguinte forma:

Tabela 1. Cronograma de execução de atividades

\begin{tabular}{|c|c|c|c|c|c|c|}
\hline Atividades & สี & 总 & $\dot{\bar{\Xi}}$ & $\grave{\frac{b}{4}}$ & 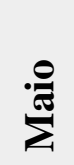 & $\Xi$ \\
\hline $\begin{array}{l}\text { Alfabetização em } \\
\text { computadores. utilizando o } \\
\text { Software Tux paint. }\end{array}$ & & & & & & \\
\hline $\begin{array}{l}\text { Leitura e escrita utilizando o } \\
\text { Software Openoffice Writer. }\end{array}$ & & & & & & \\
\hline $\begin{array}{l}\text { Raciocínio lógico utilizando } \\
\text { o Software Tuxmath }\end{array}$ & & & & & & \\
\hline
\end{tabular}

\section{Resultado e Discussão}

Nas primeiras aulas eram perceptíveis as dificuldades que os alunos tinham em utilizar o computador, pois, a maioria dos alunos eram idosos que trabalhavam o dia todo no campo e nunca tiveram nenhum tipo de contato com a tecnologia. Além da dificuldade financeira que era a principal barreira para todos os alunos que não tinham um computador em casa e por conta disso nunca tiveram acesso. Deparamo-nos também com alunos que não sabiam ler nem escrever, aumentando mais ainda a dificuldade na utilização do computador. Para Cunha (2016): 
VI Congresso Brasileiro de Informática na Educação (CBIE 2017)

Anais do XXIII Workshop de Informática na Escola (WIE 2017)

\begin{abstract}
A Educação de Jovens e Adultos (EJA) é uma modalidade de ensino composta por educandos que por suas condições históricas de exclusão não tiveram formação escolar na idade certa, este processo acontece lentamente e carece de uma maior atenção. Os integrantes deste público, já excluídos socialmente por não saberem ler e escrever, mediante o surgimento das TICs tornam-se também, excluídos digitais. Desse modo, promover o acesso e a utilização significativa das tecnologias, lhes possibilitará desenvolver habilidades e competências que contribuirão para a aprendizagem e para uma melhor integração social. Sendo assim, práticas de inclusão digital na EJA, tornam-se necessárias e altamente relevantes (CUNHA, 2016).
\end{abstract}

Gadotti (2008) afirma que "os jovens e adultos trabalhadores lutam para superar suas condições precárias de vida (moradia, saúde, alimentação, transporte, emprego, etc.) que estão na raiz do problema do analfabetismo". Percebe-se então, que estes educandos se encontram normalmente em situação de vulnerabilidade econômica, sentem-se discriminados, oprimidos e excluídos socialmente e procuram superar todas essas dificuldades através da educação.

Pensando nisso, foram escolhidos Softwares para auxiliar o aprendizado de cada dificuldade observada e dita pelas professoras. As principais dificuldades relatadas eram no raciocínio lógico e na leitura e escrita e como eles não tinham nenhum tipo de contato com o computador, escolhemos um Software que treinasse o manuseio e a interação com máquina. A partir das aplicações desses Softwares começamos a enxergar os resultados rapidamente, como podemos ver na figura 1, onde temos dois alunos idosos que nunca tiveram contato com a máquina, conseguindo manusear o mouse fazendo desenhos no Tux Paint. Já na figura 2, vemos o primeiro aluno no Software Openoffice Writer identificando as letras no teclado e digitando as palavras que eram ditadas pelos bolsistas e a segunda aluna no Tuxmath treinando o raciocínio lógico de maneira lúdica.
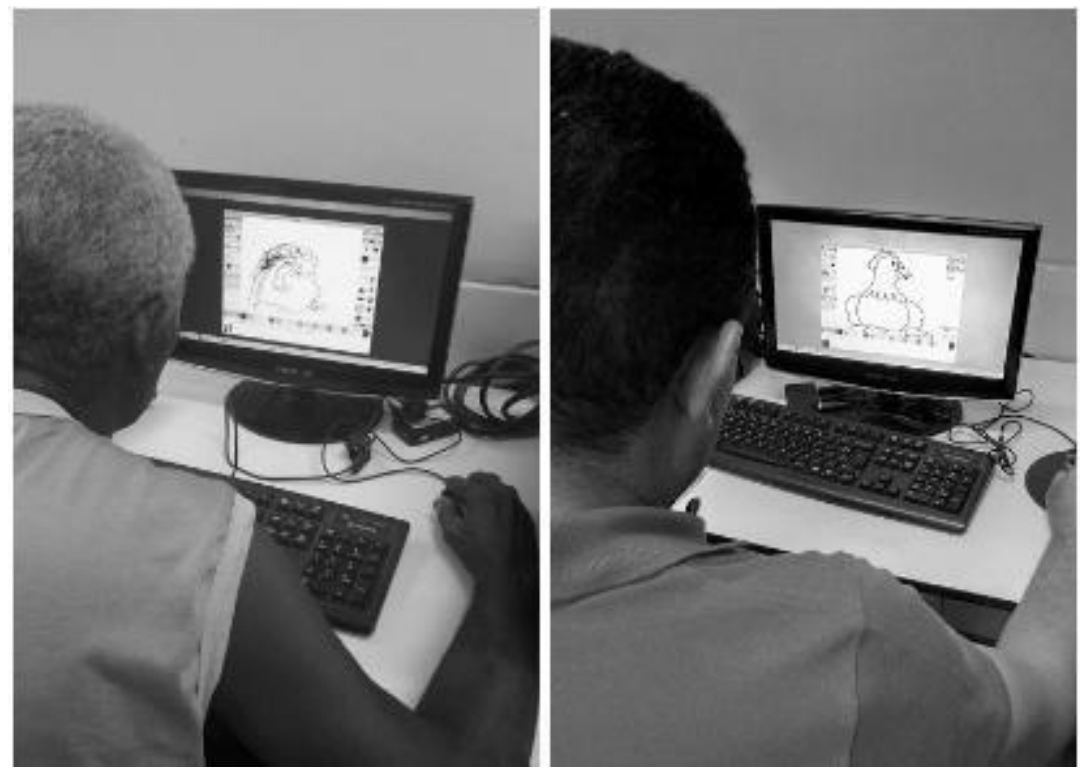

Figura 1. Alunos utilizando o TuxPaint como auxílio de manuseio do mouse e interação com o computador. 
VI Congresso Brasileiro de Informática na Educação (CBIE 2017)

Anais do XXIII Workshop de Informática na Escola (WIE 2017)

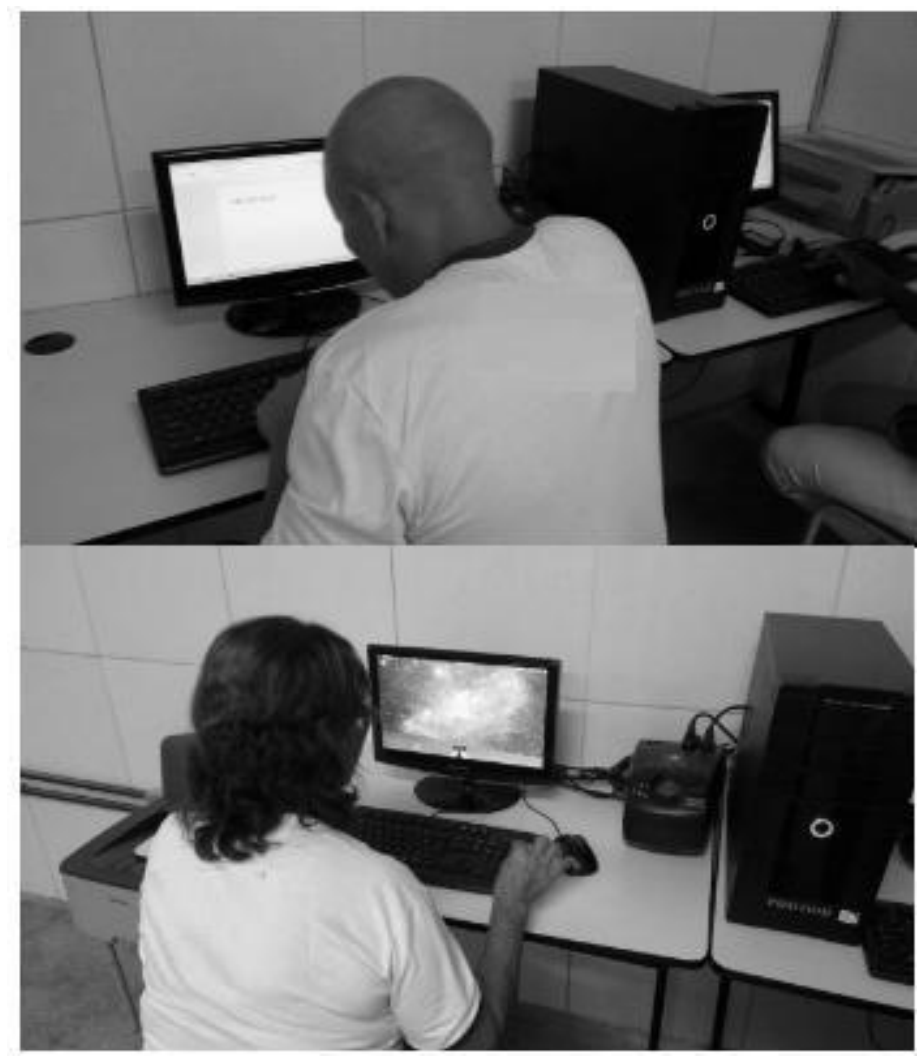

Figura 2. Alunos utilizando o Openoffice Writer como auxílio da leitura e escrita e o Tuxmath como auxílio na aprendizagem da matemática.

Após as aplicações no final do semestre, fizemos um pequeno questionário para analisar a opinião dos alunos sobre a utilização dos Softwares do Linux Educacional no ensino aprendizado. Obtemos os seguintes resultados:

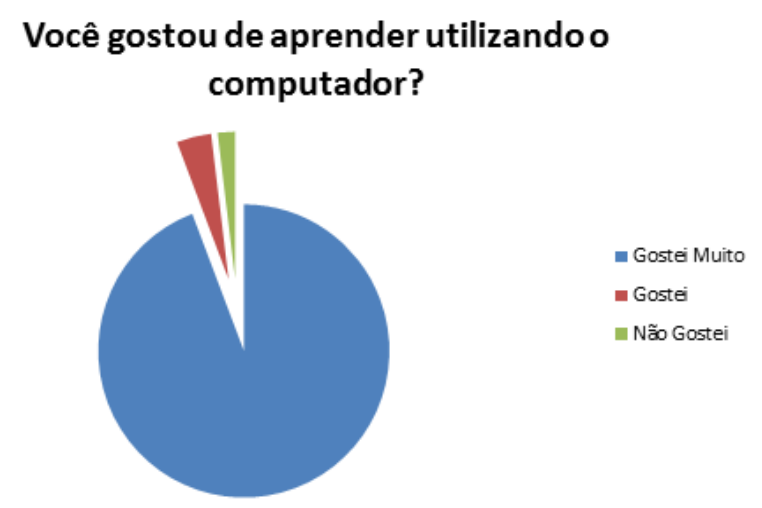

Gráfico 1. Alunos que gostaram de aprender utilizando o computador. 
VI Congresso Brasileiro de Informática na Educação (CBIE 2017)

Anais do XXIII Workshop de Informática na Escola (WIE 2017)

No Gráfico 1, podemos ver que $98 \%$ dos alunos gostaram de aprender utilizando o computador ou seja, eles ficaram motivados em aprender enquanto 1,9\% não gostou.

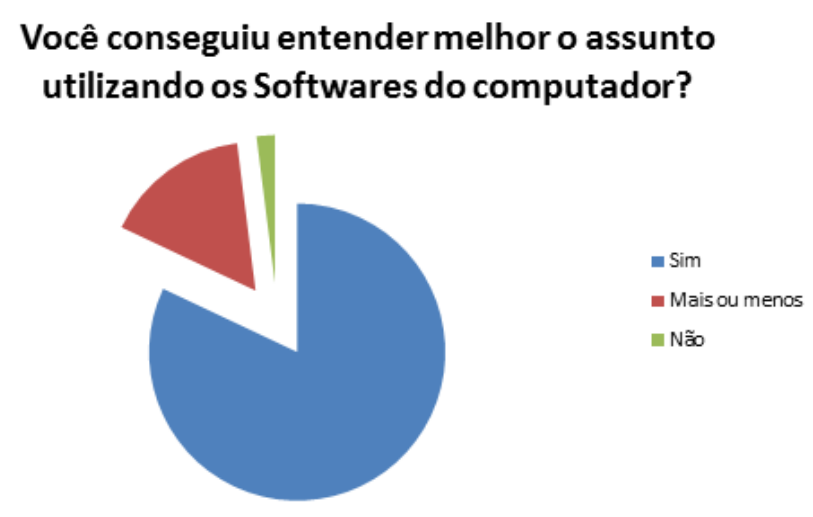

Gráfico 2. Aprendizado utilizando os Softwares

Já no Gráfico 2, foi perguntado se eles conseguiram entender melhor o assunto utilizando os Softwares do computador. Vale ressaltar que foi explicado para eles o que eram os Softwares que eles utilizaram. Vimos que 78,8\% disse que conseguiu aprender melhor com os Softwares e 1,9\% disse que não.

\section{Você gostaria que seu professor(a) utilizasse os computadores para ensinar os conteúdos das matérias?}

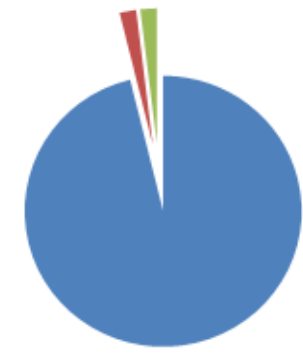

॥ Sempre

- Ásvezes

nunca

\section{Gráfico 3. Alunos que gostariam que o professor utilizasse o computador nos conteúdos das matérias.}

No Gráfico 3 foi perguntado aos alunos se eles gostariam que seus professores utilizassem o computador para ensinar os conteúdos das matérias e $96,1 \%$ responderam que gostariam que os professore sempre utilizasse os computadores para o ensino. $\mathrm{E}$ $1,9 \%$ disse que não gostaria.

Além do questionário, as professoras das turmas relataram que os alunos estavam tendo resultados muito satisfatórios, pois, elas estavam conseguindo observar os resultados nas provas que foram realizadas durante o semestre e também na participação e atenção na sala de aula. Relataram também que os alunos sempre esperavam ansiosamente pela aula de informática. 
VI Congresso Brasileiro de Informática na Educação (CBIE 2017)

Anais do XXIII Workshop de Informática na Escola (WIE 2017)

\section{Conclusão}

Logo, percebe-se que, a inclusão digital não só na EJA, mas, como também, em qualquer outro lugar onde haja pessoas com a carência da informática, torna-se um importantíssimo mecanismo de inclusão social, pois, a inserção do computador no processo de educação dos mesmos, não deve ser algo obsoleto, e sim, um instrumento pedagógico a serviço do processo de construção de um conhecimento autônomo e criativo.

Os alunos atendidos possuíam idade entre 17 e 60 anos, e a maioria deles afirmaram que só tinham o contato com o computador e com a informática em si, apenas nas aulas que foram realizadas durante o semestre, e os mesmos apresentaram dificuldades no manuseio do equipamento, já que não tinham tanto contato com o computador, logo, a realização das aulas promoveu a inclusão digital desses jovens e adultos. Foi muito gratificante para nós bolsista poder incluir esses alunos na era tecnológica, compartilhar essas experiências que o PIBID nos proporciona. Além disso, as professoras das turmas aderiram à utilização do Linux educacional para auxiliar as matérias que elas ministram.

Portanto, conclui-se que, as aulas realizadas durante o semestre, usando as ferramentas do Linux educacional, proporcionaram aos estudantes uma maior proximidade ao computador, logo, sendo incluídos ao mundo digital; desenvolveram habilidades no manuseio da máquina, como também, habilidades ao processo cognitivo com os softwares educacionais da plataforma Linux. No entanto, o processo de ensinoaprendizagem com os recursos tecnológicos foi aplicado com eficiência, gerando então, resultados esperados e atingindo o objetivo do presente artigo, e com isso, espera-se que as metodologias usadas, sejam engajadas em futuros projetos para que possam permear a construção de conhecimento que se faz no espaço educativo.

\section{Referências}

ARAÚJO, L.; FREIRE, K. X. Proinfo integrado: a formação em Linux Educacional no DF. IX Congresso Nacional de Educação - EDUCERE. III Encontro Sul Brasileiro de Psicopedagogia. PUCPR- 2009

Basto, D. L. R. (2016) "Integrando QR Code na educação na EJA: um projeto piloto voltado para entendimento da língua portuguesa". In: Anais do XXII Workshop de Informática na Escola (WIE 2016)

BRASIL. (1996) Lei de Diretrizes e Bases da Educação nº 9.394, de 20 de dezembro de 1996", Estabelece as diretrizes e bases da educação nacional.

CARVALHO, G.S.; FERREIRA, B.J.P. Software Livre Aplicado em Informática Educativa nas Escolas da Rede Pública Estadual do Pará. In: Anais do XXVIII Congresso da SBC. WIE Workshop sobre Informática da SBC, pág. 294 a 301, 2008.

CUNHA, R. S. (2016) "Práticas de Inclusão Digital na Educação de Jovens e Adultos: minicurso de Introdução à Informática" In: Anais do XXII Workshop de Informática na Escola (WIE 2016).

FREIRE, P. (2006) A importância do ato de ler: em três artigos que se completam. 47.ed. São Paulo: Cortez. 
VI Congresso Brasileiro de Informática na Educação (CBIE 2017)

Anais do XXIII Workshop de Informática na Escola (WIE 2017)

FREIRE, P. (1987) Pedagogia do oprimido. 17. ed. Rio de Janeiro: Paz e Terra.

LÉVY, P. (2001) A conexão planetária: o mercado, o ciberespaço e a consciência. São Paulo: Editora 34.

MACEDO, R. S. Etnopesquisa crítica, etnopesquisa-formação. Brasília: Liber Livro, 2009.

SOUSA, A. S; SOUZA, E. P; MELO, N. M. F. S. Inserção das Tecnologias da Informação e Comunicação na Escola: A Vivência do Núcleo de Tecnologia Educacional de Vitória da Conquista- Bahia. In: Anais do XVIII Simpósio Brasileiro de Informática na Educação - SBIE, p. 141-145, 2007. 